\title{
TOMADA DE DECISÃO APOIADA: O INSTRUMENTO JURÍDICO DE APOIO À PESSOA COM DEFICIÊNCIA INAUGURADO PELA LEI $N^{o} .13 .146 / 2015$
}

SUPPORT FOR DECISION-MAKING: THE LEGAL INSTRUMENT CREATED BY LAW 13.146 / 2015 TO SUPPORT PEOPLE WITH DISABILITIES

TOMA DE DECISIÓN APOYADA: EL INSTRUMENTO JURÍDICO DE APOYO A LA PERSONA CON DEFICIENCIA INAUGURADO POR LA LEY No.13.146/2015

Licença CC BY:

Artigo distribuído sob os termos Creative Commons, permite uso e distribuição irrestrita em qualquer meio desde que o autor credite a fonte original.
Resumo: Informa o conceito, finalidades, características e pressupostos da tomada de decisão apoiada, bem como do mecanismo processual para a sua aplicação. Apresenta esse instituto e a sua vinculação às premissas básicas da Convenção sobre os Direitos da Pessoa com Deficiência, quais sejam, o reconhecimento da autonomia do sujeito com deficiência em igualdade com os demais e a aplicação do modelo social de abordagem da deficiência, cuja consequência é a modificação do sistema protetivo. Migra-se de um modelo paternalista de substituição da vontade para um modelo emancipatório pautado no apoio. Com essa ratio, a tomada de decisão apoiada precisa ser compreendida sob pena de sua aplicação desvirtuada perpetuar o modelo de proteção ultrapassado que se pauta exclusivamente na exclusão da pessoa pela substituição da vontade. Quanto à natureza, a pesquisa realizada qualifica-se como básica e exploratório-explicativa, quanto aos objetivos. Quanto ao procedimento, fez-se um levantamento de dados bibliográficos e documental, focado nas decisões jurisprudenciais pertinentes ao tema.

Palavras-chave: Tomada de decisão apoiada; conceito; características e perfil funcional.

1 Doutora em Direito pela Universidade Federal de Pernambuco. Mestre em Direito pela Universidade Federal do Ceará. Professora titular da Universidade de Fortaleza. Programa de Pós-Graduação Strictu Senso em Direito (Mestrado/Doutorado) da Universidade de Fortaleza na Disciplina de Direitos de Personalidade. Professora adjunta da Universidade Federal do Ceará. Coordenadora do Grupo de Pesquisa CNPQ: Direito Constitucional nas Relações Privadas. Fortaleza, Ceará, Brasil. E-mail: joyceane@unifor.br. 


\begin{abstract}
This work outlines the concept, purposes, characteristics and assumptions of supported decision-making, and the procedural mechanism for its application. It presents this Institute and its link with the basics premises of the Convention on the Rights of the Disabled People, whatever they are, the autonomy acceptance of the disabled subject, and the application of the social model of disability, the consequence of which is the modification of the protective system. It migrates from a paternalistic model of substitution of the will to an emancipatory model based on support. With this "ratio", supported decisionmaking needs to be understood under penalty of its misused application, perpetuating the outdated protection model that is based solely on the exclusion of the person by the substitution of will. This research is qualified as basic in nature, and explanatory exploratory in terms of its goals. The procedure used is a bibliographic and documentary survey, focused on jurisprudencial decisions of relevance to the topic.
\end{abstract}

Keywords: Supported decision-making; concept; purposes and characteristics.

Resumen: Informa el concepto, finalidades, características y supuestos de la toma de decisión apoyada, bien como del mecanismo procesual para su aplicación. Presenta este instituto y su vinculación a las premisas básicas de la Convención sobre los Derechos de la Persona con Deficiencia, cualquier sea, el reconocimiento de la autonomía del sujeto con deficiencia en igualdad con los demás y la aplicación del modelo social de abordaje de la deficiencia, cuya consecuencia es la modificación del sistema protector. Se migra de un modelo paternalista de sustitución de la voluntad para un modelo emancipatorio pautado en el apoyo. Con esta ratio, la toma de decisión apoyada necesita ser comprendida bajo pena de su aplicación desvirtuada a perpetuar el modelo de protección ultrapasada que se pauta exclusivamente en la exclusión de la persona por la sustitución de la voluntad. Cuanto a la naturaleza, la investigación realizada se califica como básica y exploratoria explicativa, como a los objetivos. Cuanto al procedimiento, se hace un levantamiento de datos bibliográficos y documental, enfocado en las decisiones jurisprudenciales pertinentes al tema.

Palabras-clave: Toma de decisión apoyada; concepto; características y perfil funcional.

\title{
INTRODUÇÃO
}

Criada pela Lei no.13.146/2015, que instituiu o Estatuto da Pessoa com Deficiência ou Lei Brasileira de Inclusão, representa uma novidade que tem fundamentação última na Convenção sobre os Direitos da Pessoa com Deficiência - CDPD, tratado internacional aprovado pelo Brasil com o status de norma constitucional, que impôs uma profunda transformação na abordagem jurídica e social da deficiência. Além da novidade estrutural, o instituto representa a mudança funcional operada no sistema de proteção à pessoa com deficiência que migra de um modelo centrado na representação e substituição da vontade para um modelo firmado no apoio ao exercício da autonomia. 
Uma vez que a CDPD estabeleceu que a pessoa com deficiência tem igual capacidade civil para o gozo e o exercício dos seus direitos, determinou que a deficiência em si não pode funcionar como critério modulador dessa capacidade. Na hipótese em que o sujeito tiver alguma limitação natural, qualificável como deficiência, caberá ao Estado promover os mecanismos de apoio aptos a favorecer e facilitar o exercício de sua capacidade (art.12), em vez de contribuir para a sua completa exclusão do cenário relacional jurídico, social e político pela transposição do seu poder de decisão para um terceiro - o representante legal que lhe substitui integralmente a vontade. Embora ainda seja possível a curatela que conjuga os poderes de representação, esta medida somente deverá ser adotada em caráter extremo e subsidiário, bem temperada com as salvaguardas legais tendentes à proteção dos direitos humanos e fundamentais do curatelado.

A tomada de decisão apoiada foi o instituto que o Estado brasileiro propôs para esse fim. Sem excluir a curatela, medida extraordinária de utilização excepcional, para a qual estabeleceu contornos mais humanitários, também instituiu a TODA, que funciona como um apoio especial que se confere àquele que o requer, sem implicar qualquer modulação à capacidade civil.

Por meio de um negócio jurídico no qual consta o termo do apoio, o sujeito que entende dele necessitar, indica seus apoiadores, o objeto do apoio e o período de sua vigência, requerendo a exigida homologação judicial em um processo de jurisdição voluntária proposto perante as varas competentes para o conhecimento da curatela.

O apoiador não exerce função de representação ou assistência, cumpreIhe acompanhar o apoiado na conformação dos negócios jurídicos pertinentes ao objeto do apoio para prestar-lhe as informações e os esclarecimentos necessários, visando que possa tomar uma decisão mais segura. A especificidade da medida está na legitimidade que tem o apoiador para se insurgir judicialmente contra a consumação do negócio quando divergir do apoiado, por entender que a conclusão daquele negócio trará para estes graves prejuízos. Opondo-se judicialmente à formação do negócio, instará ao juiz para que decida, após oitiva do ministério público, se o negócio será ou não consumado. 
Mesmo com as suas características definidas em lei, a TDA vem sendo confundida com o mandato, a autocuratela, a diretiva antecipada de vontade. Não raro, também, tem sido confundida com uma espécie de curatela branda. Em termos mais objetivos, vê-se que o instituto tem sido mal interpretado quanto ao seu aspecto funcional nuclear - a promoção da autonomia do apoiado. Trata-se de medida personalíssima, cuja legitimidade ativa para requerer é exclusiva da pessoa que precisa do apoio. Somente se esta desejar e quando desejar poderá requerer uma TDA. Jamais poderá o juiz converter um pedido de curatela em TDA ou admitir que terceiro a requeira, ainda que seja o ministério público. Em virtude dessas questões, este artigo apresenta a sistematização dos contornos conceituais do instituto, explicando as diferenças específicas que guarda em relação às figuras jurídicas com as quais possa ter alguma semelhança. Ao final, destaca a conveniência de se admitir a instituição da TDA por meio de escritura pública, em atenção aos comandos da Organização das Nações Unidas quanto à promoção da autonomia da pessoa.

\section{EM QUE CONSISTE A TOMADA DE DECISÃO APOIADA?}

Instituída pela Lei no.13.146/2015, ${ }^{2}$ a tomada de decisão apoiada é uma resposta à Convenção sobre os Direitos da Pessoa com Deficiência (CDPD), que impôs aos Estados signatários a adoção de medidas apropriadas para promover o apoio às pessoas com deficiência, no escorreito exercício de sua capacidade civil (art.12, item 3). ${ }^{3}$ Segue a ratio dessa Convenção que reconhece a liberdade, a autonomia e a independência dessas pessoas para realizarem as suas próprias

2 A tomada de decisão apoiada foi introduzida ao PL n.7.699/2006, por meio da Ementa de Plenário n. 05/2014, assinada pelo então Deputado Federal mineiro Eduardo Barbosa (PSDB), sugestão acatada pela relatora do projeto naquela Casa, Deputada Federal Mara Gabrilli (PSDB-SP) e aprovada pela unanimidade dos votos dos presentes. Na justificativa apresentada pelo Deputado, tem-se a menção expressa ao art.18, da Convenção que evoca a necessidade de se estruturarem mecanismos aptos a realização da máxima autonomia da pessoa. In verbis: "No caso da pessoa com deficiência, muitas vezes em razão de impedimentos corporais ou de barreiras socioambientais, é preciso buscar apoio de forma mais explícita. Nesse contexto, para possibilitar à pessoa com deficiência o exercício pleno de seus direitos de cidadania, a CDPD declara, expressamente, a possibilidade de obtenção de apoio, sem que essa relação de dependência caracterize inferioridade em relação às demais pessoas. Fundamentada nos princípios gerais que a norteiam, entre os quais se destacam a autonomia individual, inclusive a liberdade de fazer as próprias escolhas, a plena e efetiva participação e inclusão na sociedade e o respeito pela diferença, a Convenção inova no art. 12 ao asseverar que todas as pessoas com deficiência têm capacidade legal, inclusive para exercer seus direitos e cumprir seus deveres." (Diário da Câmara dos Deputados. Ano LXX, n. 31, 06 de março de 2015, p.163).

3 Convenção sobre os Direitos da Pessoa com Deficiência, Dec.6.949, de 25 de agosto de 2009 , "Artigo 12. Reconhecimento igual perante a lei:

1. Os Estados Partes reafirmam que as pessoas com deficiência têm o direito de ser reconhecidas em qualquer lugar como pessoas perante a lei. 
escolhas, atribuindo-se-lhes a capacidade jurídica, em igualdade de condições com as demais, ainda que lhes seja necessário assegurar algum tipo de apoio (art.12, item 2, CDPD).

Pode-se dizer que a tomada de decisão apoiada retrata muito bem o slogan "independente mas não só", bandeira de chamada do "Independent Living Movement and Disability Rights", movimento social que nasceu nos Estados Unidos, na década de 70, para fomentar e promover o direito das pessoas com deficiência a uma vida independente. ${ }^{4}$

2. Os Estados Partes reconhecerão que as pessoas com deficiência gozam de capacidade legal em igualdade de condições com as demais pessoas em todos os aspectos da vida.

3. Os Estados Partes tomarão medidas apropriadas para prover o acesso de pessoas com deficiência ao apoio que necessitarem no exercício de sua capacidade legal.

4. Os Estados Partes assegurarão que todas as medidas relativas ao exercício da capacidade legal incluam salvaguardas apropriadas e efetivas para prevenir abusos, em conformidade com o direito internacional dos direitos humanos. Essas salvaguardas assegurarão que as medidas relativas ao exercício da capacidade legal respeitem os direitos, a vontade e as preferências da pessoa, sejam isentas de conflito de interesses e de influência indevida, sejam proporcionais e apropriadas às circunstâncias da pessoa, se apliquem pelo período mais curto possível e sejam submetidas à revisão regular por uma autoridade ou órgão judiciário competente, independente e imparcial. As salvaguardas serão proporcionais ao grau em que tais medidas afetarem os direitos e interesses da pessoa.

5. Os Estados Partes, sujeitos ao disposto neste Artigo, tomarão todas as medidas apropriadas e efetivas para assegurar às pessoas com deficiência o igual direito de possuir ou herdar bens, de controlar as próprias finanças e de ter igual acesso a empréstimos bancários, hipotecas e outras formas de crédito financeiro, e assegurarão que as pessoas com deficiência não sejam arbitrariamente destituídas de seus bens. (grifo proposital).

1. Os Estados Partes reafirmam que as pessoas com deficiência têm o direito de ser reconhecidas em qualquer lugar como pessoas perante a lei.

2. Os Estados Partes reconhecerão que as pessoas com deficiência gozam de capacidade legal em igualdade de condições com as demais pessoas em todos os aspectos da vida.

3. Os Estados Partes tomarão medidas apropriadas para prover o acesso de pessoas com deficiência ao apoio que necessitarem no exercício de sua capacidade legal.

4. Os Estados Partes assegurarão que todas as medidas relativas ao exercício da capacidade legal incluam salvaguardas apropriadas e efetivas para prevenir abusos, em conformidade com o direito internacional dos direitos humanos. Essas salvaguardas assegurarão que as medidas relativas ao exercício da capacidade legal respeitem os direitos, a vontade e as preferências da pessoa, sejam isentas de conflito de interesses e de influência indevida, sejam proporcionais e apropriadas às circunstâncias da pessoa, se apliquem pelo período mais curto possível e sejam submetidas à revisão regular por uma autoridade ou órgão judiciário competente, independente e imparcial. As salvaguardas serão proporcionais ao grau em que tais medidas afetarem os direitos e interesses da pessoa.

5. Os Estados Partes, sujeitos ao disposto neste Artigo, tomarão todas as medidas apropriadas e efetivas para assegurar às pessoas com deficiência o igual direito de possuir ou herdar bens, de controlar as próprias finanças e de ter igual acesso a empréstimos bancários, hipotecas e outras formas de crédito financeiro, e assegurarão que as pessoas com deficiência não sejam arbitrariamente destituídas de seus bens. (grifo intencional).

4 A discussão sobre "sujeitos de direitos" tem sido recobrada nos últimos anos com a maior reflexão sobre os direitos humanos. Estudos sobre cidadania e não discriminação questionam a posição que certos grupos de pessoas, a exemplo das mulheres, das crianças e das pessoas com deficiência ocupam no âmbito do Direito, notadamente quanto ao status da capacidade civil. Não raro, a capacidade civil se interpôs para mitigar ou negar o exercício de direitos humanos intransmissíveis e personalíssimos. É nesse cenário que a deficiência tem assumido destaque nos debates jurídicos a ponto de ser objeto de atenção legislativa em alguns países. Sob a proposta do modelo 
Em termos mais objetivos, a Tomada de Decisão Apoiada, instituída pelo art.116, da Lei no.13.146/15 que introduziu o art.1.783-A e incisos ao Código Civil Brasileiro, constitui um acordo de apoio judicialmente homologado a partir da provocação exclusiva da própria pessoa que entende dele necessitar. ${ }^{5}$ Como se trata de uma medida a ser proposta judicialmente, há necessidade de representação do proponente por meio de um advogado público ou privado. Diz o dispositivo,

Art. 1.783-A. A tomada de decisão apoiada é (1) o processo pelo qual (2) a pessoa com deficiência (3) elege pelo menos 2 (duas) pessoas idôneas, com as quais mantenha vínculos e que gozem de sua confiança, (4) para prestarIhe apoio na tomada de decisão sobre atos da vida civil, fornecendo-lhes os elementos e informações necessários para que possa exercer sua capacidade.

Embora seja destinada exclusivamente à pessoa com deficiência, conforme se pode extrair da própria justificativa para a introdução do instituto na lei (nota de rodapé $n^{\circ} 1$ ), entende-se possível a sua aplicação às pessoas idosas e àquelas que sofrem os efeitos da adição por álcool e/ou outras drogas. Sujeitos que ainda possuem capacidade civil, mas que, em virtude de dificuldades individuais específicas, necessitariam de um apoio mais objetivo. Nesse aspecto, a TDA funcionaria como uma alternativa à antiga curatela sem interdição assentada no art. 1.780, revogado recentemente pelo Estatuto da Pessoa com Deficiência. Muito embora dela distinta porque também não se presta a representar ou a assistir.

Sem restringir a capacidade civil da pessoa que a requer, a TDA, do contrário, consiste na implementação de um apoio ao melhor exercício da autonomia, seja na seara existencial ou patrimonial, nos termos que for fixado pelo projeto de apoio requerido. Não implica assistência ou representação, tampouco

social de abordagem da deficiência, a produção legislativa deve se pautar na busca da igualdade, buscando compreender a deficiência não como uma situação ou circunstância, mas como um traço de identidade (ROIG, Rafael Asís. Sobre capacidade y derechos. In: AVILÉS, María del Carmen Barranco; ANGÓN, Oscar Celador y FERNANDEZ, Félix Vaca (Coord.). Perspectivas atuales sobre los sujetos de derechos. Dikinson: Madrid, 2012, p.38-39).

5 Neste sentido, a decisão do TJRS é firme em sustentar a legitimidade exclusiva da pessoa para requerer a TDA. Ementa: APELAÇÃO CÍVEL. INTERDIÇÃO. CAPACIDADE CIVIL. EXISTÊNCIA. IMPROCEDÊNCIA DO PEDIDO. TOMADA DE DECISÃO APOIADA. DESCABIMENTO, NO CASO. 1. No caso, deve ser mantida a sentença de improcedência do pedido de interdição, porquanto a prova pericial atesta a capacidade do réu para a prática dos atos da vida civil. 2. Considerando que a legitimidade para requerer a tomada de decisão apoiada é exclusiva da pessoa a ser apoiada (inteligência do art. 1.783-A do CCB), não possui a apelante legitimidade ativa para requerêlo, sopesado que o réu é pessoa capaz. APELAÇÃO DESPROVIDA. (Apelação Cível No 70072156904, Oitava Câmara Cível, Tribunal de Justiça do RS, Relator: Ricardo Moreira Lins Pastl, Julgado em 09/03/2017). 
em transferência de atos de gestão, mas no apoio. Se o sujeito necessitar de assistência ou representação relativamente à prática de determinados atos da vida civil já não poderá se valer, para esse fim, da tomada de decisão apoiada. A solução mais apropriada ao seu caso será a da curatela.

\section{AUTOCURATELA, MANDADO E DIRETIVA ANTECIPADA DE VONTADE: FIGURAS PRÓXIMAS OU LONGÍNQUAS?}

A tomada de decisão apoiada não se confunde com a autocuratela, o mandato (CC, art. 653) ou com a diretiva antecipada de vontade (Conselho Federal de Medicina editou a Resolução no 1995/2012.). Relativamente a essas figuras, o principal fator distintivo que demarca a singularidade da TDA está no próprio aspecto formal.

A autocuratela pode ser compreendida um negócio jurídico atípico, não solene, de iniciativa da própria pessoa, fruto de sua autonomia negocial, no qual constam decisões pertinentes às questões específicas de sua vida patrimonial e existencial a serem aplicadas na hipótese de perder a capacidade volitiva. ${ }^{6}$ Dentre essas decisões, inclui-se a nomeação do curador e os poderes específicos que este deve receber para representá-lo ou assisti-lo.

Embora seja um negócio não solene, recomenda-se a sua feitura por meio de escritura pública para fortalecer a prova de sua veracidade, ao tempo em que tiver de ser cumprida. Pois, à semelhança da Diretiva Antecipada de Vontade, a autocuratela expressa uma autonomia prospectiva, ${ }^{7}$ voltada a produzir efeitos no futuro, ante o acontecimento de um evento incerto, como a superveniente ausência de discernimento.

Nessa mesma direção, a autotutela é permitida no direito civil Espanhol, como uma alternativa muito adequada às pessoas que têm a consciência de uma saúde mental comprometida a médio prazo por uma doença degenerativa. Para defender esse direito, o espanhol Eloy Sánchez Torres tomou como referência

$6 \quad$ TEIXEIRA, Ana Carolina Brochado; RETTORE, Anna Cristina de Carvalho e SILVA, Beatriz de Almeida Borges e. Reflexões sobre a autocuratela na perspectiva dos planos do negócio jurídico. In: MENEZES, Joyceane B. Direito da pessoa com deficiência intelectual e psíquica nas relações privadas. Convenção sobre os direitos da pessoa com deficiência e Lei Brasileira de Inclusão. Rio de Janeiro: Processo, 2016.

7

TEIXEIRA et al. Op. cit., p.316. 
o caso reconhecido pelos tribunais russos que analisou o caso de um jovem diagnosticado com uma doença degenerativa.

Se trataba del caso de un joven ruso, Ivon Cnimzo, que sufría una enfermedad hereditaria degenerativa incurable ligada a la edad. El mismo día en que alcanzaba la mayoría de edad autorizó un documento privado en el que nombraba tutor a un vecino amigo suyo para el caso de que el temido momento de su locura aconteciera, como así ocurrió. En el documento dispuso que «por si en mi naturaleza encuentra exteriorización en su día, la enfermedad, en mi probablemente latente, de mis padres, yo, ciudadano ruso, mayor de edad, declaro mi deseo de que si algún día es preciso..., sean mis tutores....»8

A ressalva é a de que o negócio puro e simples não opera, por si, a instituição da curatela. Para tanto, é necessária a propositura da ação de curatela e a juntada dessa manifestação de vontade anterior para que se faça a sua acolhida. Tudo sob o crivo do ministério público e do juiz. Foi exatamente assim que se fez em relação ao jovem russo acima mencionado.

Llegado el momento de locura, se planteó ante la justicia rusa la validez de tal estipulación: ¿una persona mayor de edad podía nombrar para el futuro a su propio tutor? La justicia resolvió reconociendo la legalidad del documento suscrito por Ivon Cnimzo, tanto en sus aspectos personales como patrimoniales. ${ }^{9}$

Com a versão inicial do EPD, atribuiu-se ao art.1.769, IV do Código Civil uma redação que admitia a legitimidade ativa da própria pessoa na propositura de sua curatela e, consequentemente, indicação do curador e respectivos poderes, configurando-se, portanto, uma espécie de autocuratela. ${ }^{10}$ Sob uma ou outra

8 HERNANDEZ, Angel Sanchez. El artículo 223.2. ${ }^{\circ}$ del Código Civil: La autotutela y su necesidad en nuestra sociedad. Revista Crítica de Derecho Inmobiliario, N. ${ }^{\circ} 736$, págs. 861 a 886 . Disponivel em: < https://librosrevistas-derecho.vlex.es/vid/arta-culo-civil-autotutela-necesidad-439674310>. Acesso em: 12 dez. 2017.

9 HERNANDEZ, Angel Sanchez. El artículo 223.2. ${ }^{\circ}$ del Código Civil: La autotutela y su necesidad en nuestra sociedad. Revista Crítica de Derecho Inmobiliario. N. ${ }^{\circ} 736$, págs. 861 a 886 . Disponível em: < https://librosrevistas-derecho.vlex.es/vid/arta-culo-civil-autotutela-necesidad-439674310>. Acesso em: 12 dez. 2017.

10 Embora o Código de Processo Civil haja revogado esse dispositivo, entende-se que sob a perspectiva da legalidade constitucional, ainda seria possível se falar em autocuratela. Sobre esse tema, vale a leitura do capítulo escrito pela Professora Paula Greco Bandeira, intitulado "Notas sobre a autocuratela e Estatuto da Pessoa com Deficiência" (In: MENEZES, Joyceane Bezerra de. Direito da pessoa com deficiência nas relações privadas. Processo: Rio de Janeiro, 2016, p. 569). 
perspectiva, a autocuratela é bem distinta da tomada de decisão apoiada, quanto ao fim e à forma.

Trata-se de um ato de autonomia prospectivo que visa à indicação de curador e os poderes a este transmitidos. Enquanto a TDA é um negócio jurídico de aplicação imediata, após a sua homologação judicial para um fim específico, nomear apoiador que não tem poderes de representação ou assistência, mas apenas o dever de apoiar nos termos que o acordo estabelecer. Nada obsta a que o termo de apoio possa ter uma cláusula específica de fixação da autocuratela, indicando, inclusive, os próprios apoiadores como curadores futuros.

O mandato e a diretiva antecipada de vontade, por seu turno, são resultantes de um negócio jurídico não solene, enquanto a tomada de decisão apoiada se estabelece por meio de um negócio jurídico homologado judicialmente em procedimento de jurisdição voluntária. No aspecto material, a diferença continua, haja vista que cada uma delas possui objeto específico e não coincidente.

Nos contratos de mandato, há a transmissão de poderes de representação contratual (art.653 e segs, Código Civil) que não se observa no âmbito da tomada de decisão apoiada. Repisa-se que o acordo de decisão apoiada visa conceder apenas o suporte necessário ao apoiado, para que este possa realizar as escolhas mais seguras e adequadas aos seus interesses sem riscos de graves prejuízos. Não cabe ao apoiador agir em nome do apoiado, este continua sendo o protagonista das suas escolhas e o agente dos negócios jurídicos.

O apoiador é um facilitador que deve explicar melhor os termos, o negócio e as suas consequências, para que o apoiado tome decisões mais seguras. Diverge de um mero consultor, porque terá legitimidade processual ativa para, por meio de oposição dirigida ao juiz, intervir na consolidação da avença, se entender que esta trará graves riscos aos interesses existenciais ou patrimoniais do apoiado (art.1.783-A, §6º). No mandato, por sua vez, o outorgado age em nome do outorgante e, uma vez que aceitou essa representação, não tem o poder de discordar do conteúdo da vontade do mandatário para agir de modo distinto. Se assim ocorrer, o máximo que pode fazer é declinar dos poderes que Ihes foram conferidos. 
Regra geral, o mandado só transmite poderes de administração (art. 662, CC). A transmissão de poderes para alienar, hipotecar, transigir ou praticar quaisquer atos que transbordem da administração ordinária exigirá procuração com poderes especiais e expressos (art. 661, parágrafo primeiro, CC). Mandados que tocam aspectos existenciais como os poderes para representar o nubente no requerimento e na celebração do casamento também exigem que a procuração seja específica (art. 1.542, CC).

Se o mandatário exceder os poderes outorgados ou agir contra eles, será considerado mero gestor de negócios, enquanto o mandante não lhe retificar os atos (art. 665). E quanto a esse aspecto, o gestor de negócios será pessoalmente responsável para com as pessoas com quem tratar (art. 861, CC) e para com o próprio dono do negócio (art. 863 e art. 866 e segs, CC).

A diretiva antecipada de vontade tem por objeto específico a garantia de se respeitar o desejo do paciente quanto ao tratamento que pretende ou não receber quando estiver sem condições de decidir livre e autonomamente sobre isso. Nos termos da Resolução 1995/2012 do Conselho Federal de Medicina, engloba o testamento vital e a representação de saúde. Por meio de testamento vital, a pessoa informa previamente o tipo de cuidados e tratamentos que deseja ou não receber e essa vontade deve ser respeitada quando ela já não estiver em condições clínicas para decidir. Poderá, de outro modo, apenas indicar um representante, a fim de que este possa decidir em seu nome quando já não puder fazê-lo (art. $2^{\circ}, \S 1^{\circ}$ ).

Em nada esse instituto se assemelha à TDA. Exceto quanto ao fato de que a TDA pode estabelecer o apoio para decisões pertinentes à esfera da saúde do apoiado. Apoio, mas não representação legal ou contratual. Nesse aspecto, caberá ao apoiador esclarecer todos os elementos circundantes às escolhas que o apoiado precisar fazer nesta seara. Mas mesmo assim, o apoiador não poderá, por isso, decidir em seu nome. Diferente da diretiva antecipada de vontade, a TDA somente subsistirá em seus efeitos enquanto a pessoa estiver no exercício da plena capacidade civil.

A EXIGÊNCIA DA HOMOLOGAÇÃO JUDICIAL DO APOIO EM 
O pedido de homologação do acordo de apoio para a tomada de decisão será dirigido ao juízo competente para conhecer da ação de curatela e nele constará: o objeto do apoio; o prazo de sua vigência; a designação de dois ou mais apoiadores que devem ser pessoas idôneas, da confiança do requerente e com quem este mantenha vínculos; bem como o compromisso destes apoiadores em respeitar a vontade, os direitos e os interesses da pessoa apoiada. Como se trata de um acordo de apoio, o requerente e os apoiadores devem assinar o termo.

À revelia da lei e da ratio da própria Convenção, há quem entenda possível atribuir a iniciativa da TDA a um terceiro. Mas não é o caso. Nem o MP teria essa legitimidade, ${ }^{11}$ tampouco poderia o juiz, de ofício, converter um pedido de curatela em decisão apoiada.

11 O agravo de instrumento abaixo numerado reformou decisão da juíza a quo que, dentre outras medidas, instava o Ministério Público a tomar providências cabíveis, inclusive, sendo o caso, a propositura da tomada de decisão apoiada ou a interdição. Relatório do Agravo dispõe: "Trata-se de agravo de instrumento interposto por BANRISUL em face da decisão que, nos autos da ação declaratória de nulidade de contratos e inexistência de débitos que lhe move ROSALVA FERNANDES VILLARINHO, assim dispôs: Anote-se a tramitação preferencial. Defiro AJG. Tratase de ação declaratória de nulidade de contratos e de inexistência de débito, em que a parte autora, diagnosticada com doença bipolar (perturbação maníaca) desde 1997, postula, em tutela provisória a suspensão de descontos na conta corrente ou na folha de pagamento da autora, referentes a lançamento de juros de cheque especial, compras com Banricompras, operações com cartão de crédito e seus respectivos juros, título de capitalização e seguros de vida deduzidos de sua conta, bem como para que a parte adversa se abstenha de impedir/bloquear o uso do cartão bancário da autora ou restrinja seu uso. É relato. Passo a decidir. Considerando que os empréstimos realizados pela autora podem comprometer a sua subsistência, bem como os fortes indícios de que ela seja portadora de doença mental grave, a priori, enquadrando-se no conceito de pessoa com deficiência, nos termos do art. $2^{\circ}$, da Lei $n^{\circ}$ 13.146/2015, é de ser deferida a tutela provisória pretendida, tendo em vista o perigo de dano, já que a autora reside em residencial geriátrico (fl. 25) e necessitada dos valores creditados em sua conta para promover o seu sustento, preservando-se o seu direito à saúde e à moradia, garantidos pelo Estatuto da Pessoa com Deficiência. Ante o exposto, DEFIRO a suspensão de descontos na conta corrente ou na folha de pagamento da autora, referentes a lançamento de juros de cheque especial, compras com Banricompras, operações com cartão de crédito e seus respectivos juros, título de capitalização e seguros de vida deduzidos de sua conta, bem como para que a parte adversa se abstenha de impedir/bloquear o uso do cartão bancário da autora ou restrinja seu uso, tudo sob pena de multa diária no valor de $R \$ 500,00$, a ser consolidada em 30 dias. Intimem-se. Cite-se o réu para contestar o feito, no prazo legal, tendo em vista o desinteresse na designação de audiência. 3. Após, remetam-se os autos ao Ministério Público, a fim de que promova as medidas cabíveis, verificando, se há pertinência em se promover a tomada de decisão apoiada, art. 1.783-A do Código Civil, ou a interdição. Dil. Legais. (... ). O agravo foi acolhido, determinando-se a reforma a decisão interlocutória, sendo a ementa: "AGRAVO DE INSTRUMENTO. NEGÓCIOS JURÍDICOS BANCÁRIOS. AÇÃO DECLARATÓRIA DE NULIDADE DE CONTRATOS E INEXISTÊNCIA DE DÉBITOS. INCAPACIDADE PARA OS ATOS DA VIDA CIVIL À ÉPOCA DA CONTRATAÇÃO. PROVA. AUSENCIA. PREENCHIMENTO DOS REQUISITOS DOS ARTS. 300 E/OU 311 DO CPC/15. NÃO VERIFICADOS. MATÉRIA DE FATO. CASO CONCRETO. No caso, o suporte probatório constante neste recurso não é bastante para o deferimento da tutela antecipatória pleiteada, pois ausentes os requisitos previstos pelos arts. 300 e/ou 311 do CPC/15. Necessidade de oportunizar a parte demandada o contraditório." AGRAVO DE INSTRUMENTO PROVIDO. (Agravo de Instrumento No 70070005459, Décima Quinta Câmara Cível, Tribunal de Justiça do RS, Relator: Adriana da Silva Ribeiro, Julgado em 13/07/2016). (TJ-RS - Al: 70070005459 RS, Relator: Adriana da Silva Ribeiro, Data de Julgamento: 13/07/2016, Décima Quinta Câmara Cível, Data de Publicação: Diário da Justiça do dia 18/07/2016). 
Nada obsta, porém, que o juiz, ao conhecer o pedido de curatela, possa denegá-lo e recomendar a solução da Tomada de Decisão Apoiada, se entender que esta seria a alternativa mais apropriada à situação. ${ }^{12}$ Caso específico decidido pelo Tribunal de Justiça de São Paulo, ao examinar o pedido de curatela de uma pessoa deficiente visual, denegou a medida em virtude do verificado pleno discernimento do curatelando. Como o pleito tinha correlação com a exigência desarrazoada do Instituto Nacional da Seguridade Social (INSS) da prévia interdição para conceder o benefício da assistência social (LOAS), o julgador recomendou a solução da Tomada de Decisão Apoiada, dizendo que esta já seria suficiente para aquele fim. ${ }^{13}$ Ainda neste aspecto, discorda-se da solução apontada. Da tomada de decisão apoiada não se pode deduzir uma incapacidade laboral. Mas também não há, em todo o ordenamento jurídico, a exigência da prova da "incapacidade civil" para a concessão do benefício assistencial.

Poderia o juiz, nos autos da ação de curatela, entendendo a inadequação de uma medida tão extrema, antes de extinguir a ação, intimar a pessoa do curatelando, para que este viesse a manifestar eventual interesse pela decisão apoiada e, seguidamente, apresentar um termo de acordo para homologação com os indicados apoiadores. ${ }^{14}$ Não lhe é facultado, porém, determinar a

\section{conversão da curatela em TDA e à revelia do interessado.}

12 Curatela - Interditanda idosa, deficiente física, com sequelas de AVC - Ausência de incapacidade permanente ou transitória que afete a manifestação da vontade - Laudo pericial que aponta pela habilidade de prática dos atos da vida civil - Caso em que não se verifica incapacidade relativa, o que desautoriza o estabelecimento de curatela - Limitação de direitos da pessoa sobre sua própria gestão que, com a introdução das alterações realizadas pelo Estatuto da Pessoa com Deficiência, se tornou medida excepcionalíssima - Hipótese em que outros meios jurídicos, como o mandato ou tomada de decisão apoiada, se mostram mais adequados à pretensão da filha sobre a genitora e gestão de seus negócios - Sentença mantida - Recurso improvido. (TJ-SP - APL: 00062903320138260242 SP 0006290-33.2013.8.26.0242, Relator: Eduardo Sá Pinto Sandeville, Data de Julgamento: 02/06/2016, 6ª Câmara de Direito Privado, Data de Publicação: 02/06/2016).

13 Curatela Interditando cego, em decorrência de diabete mellitus. Ausência de incapacidade permanente ou transitória que afete a manifestação da vontade. Laudo pericial que aponta pelo discernimento do periciando. Caso em que não se verifica incapacidade relativa, o que desautoriza o estabelecimento de curatela. Limitação de direitos da pessoa sobre sua própria gestão que, com a introdução das alterações realizadas pelo Estatuto da Pessoa com Deficiência, se tornou medida excepcionalíssima. Termo de curatela de beneficiário com deficiência que não mais pode ser exigido pelo INSS Art. 110-A, da Lei n 8.213/91. Hipótese em que outros meios jurídicos, como o mandato ou tomada de decisão apoiada, se mostram mais adequados. Sentença mantida. Recurso improvido. (TJSP. APEL.No: 0056408-81.2012.8.26.0554. Relator Des. Eduardo Sá Pinto Sandeville)

14 Neste outro julgado do Tribunal de Justiça do Estado de Roraima, afirmou-se a possibilidade de conversão da Ação de curatela em tomada de decisão apoiada, a depender da vontade da pessoa interessada após a devida intimação. Segundo o relator, "Assim, para os casos de processo de interdição e curatela em curso, a solução proposta é observar os limites impostos pelo novo Estatuto e consignar os limites de atuação do curador no termo de curatela. Ou ainda a conversão do procedimento para tomada de decisão apoiada, novo instituto acrescido pelo Estatuto, descrito no novel art. $\underline{1.783-A}$ do Código Civil. Deste modo, faz-se necessário a adoção por uma ou outra medida. Entendo que o juízo de origem possui maior substrato para tanto, que deve concitar intimar as partes neste sentido." A Ementa do julgado segue transcrita: "Apelação Cível. Interdição e curatela. Estatuto da Pessoa com Deficiência. Conversão para tomada de decisão. Limites. Com a entrada em vigor do Estatuto da Pessoa com Deficiência os processos de interdição em trâmite podem ser convertidos para tomada de decisão apoiada ou ainda consignado os limites da curatela. (Apelação, Processo n 0001370-73.2015.822.0010, Tribunal de Justiça do Estado de Rondônia, 2ª Câmara Cível, Relator (a) do Acórdão: Des. Alexandre Miguel, Data de julgamento: 28/04/2016). 
A despeito da deficiência, a pessoa que requer a "decisão apoiada" NÃO SOFRE RESTRIÇÃO À SUA CAPACIDADE, mantém íntegras a sua capacidade volitiva e a sua autonomia, razão pela qual não se justifica a intrusão de um terceiro ou do Estado na sua vida pessoal e negocial para impingi-la um apoio que ela própria não quer receber.

No documento intitulado "Observações finais sobre o informe inicial do Brasil", o "Comitê da ONU sobre os Direitos das Pessoas com Deficiência" expressou a preocupação com o fato de algumas leis ainda utilizarem a lógica do sistema de substituição de vontade, em oposição ao que dispõe o art.12, e que os procedimentos de apoio para a adoção de decisões requeiram aprovação judicial, desprestigiando a autonomia, a vontade e as preferências das pessoas com deficiência. In verbis,

Igual reconocimiento como persona ante la ley (art. 12)Preocupa al Comité que algunas leyes del Estado parte sigan contemplando, en ciertas circunstancias, la sustitución en la adopción de decisiones, que es contraria al artículo 12 de la Convención, tal como se explica en la observación general núm. 1 del Comité (2014) sobre el igual reconocimiento como persona ante la ley. También le preocupa que los procedimientos de apoyo para la adopción de decisiones requieran aprobación judicial y que no primen la autonomía, la voluntad y las preferencias de las personas con discapacidad.

El Comité insta al Estado parte a que derogue todas las disposiciones legales que perpetúen el sistema de la sustitución en la adopción de decisiones. También le recomienda que adopte, en consulta con las organizaciones de personas con discapacidad y otros proveedores de servicios, medidas concretas para reemplazar el sistema basado en la adopción de decisiones sustitutiva por otro basado en el apoyo a la adopción de decisiones que privilegie la autonomía, la voluntad y las preferencias de las personas con discapacidad, en plena conformidad con el artículo 12 de la Convención. Le recomienda además que mantenga debidamente informadas sobre el nuevo marco legal a todas las personas con discapacidad que se encuentren bajo custodia, $y$ que garantice en todos los casos el ejercicio del derecho al apoyo para la adopción de decisiones. ${ }^{15}$ (grifo intencional)

15 NACIONES UNIDAS. Comité sobre los Derechos de las Personas con Discapacidad. Observaciones finales sobre el informe inicial del Brasil. Disponível em: <https://documents-dds-ny.un.org/doc/UNDOC/GEN/G15/220/78/PDF/ G1522078.pdf?OpenElement>. Acesso em: 16 set. 2017. 
Novos Estudos Jurídicos

Pode-se entender que a crítica da ONU recai sobre a judicialização do apoio para a tomada de decisão. Entre nós, a Tomada de Decisão Apoiada se consolida a partir da homologação pelo judiciário, ainda que o plano de apoio seja talhado anteriormente pela pessoa que o requer. É em face dessa crítica, e visando à garantia da mais ampla autonomia à pessoa com deficiência, que se cunharam os argumentos em favor do acordo de "decisão apoiada" por meio de escritura pública. ${ }^{16}$

\section{ASPECTOS PROCESSUAIS ESSENCIAIS}

Assistida por um advogado, a pessoa interessada deve propor a ação judicial específica com o plano de apoio que melhor se adeque às suas necessidades, no qual indicará duas ou mais pessoas de sua confiança e com as quais possua vínculo para que sejam nomeadas suas apoiadoras.

Embora a sua previsão no Código Civil seja derivada da alteração promovida pelo Estatuto da Pessoa com Deficiência, entende-se que a tomada de decisão apoiada pode ser utilizada por qualquer pessoa maior que sinta a necessidade de apoio para o exercício de sua capacidade legal, especificamente os idosos, adictos em álcool e/ou outras drogas, pessoas que tenham dificuldade para locomoção, limitadas por sequelas de acidente vascular cerebral ou aquelas que estão nas fases iniciais de doença de Alzheimer.

\section{DA LEGITIMIDADE ATIVA}

Trata-se de um ato personalíssimo, de legitimidade exclusiva daquele que dela se beneficiará, por isso deve ser requerida pelo próprio interessado e nunca por terceiros. Assim, não poderá o juiz, ex officio ou mediante provocação do Ministério Público, designar a decisão apoiada em favor do jurisdicionado, tampouco indicar novos apoiadores em substituição àqueles indicados pelo apoiado. Uma vez que se verifique a inaptidão da pessoa indicada para prestar o apoio, o beneficiário deve ser intimado para renovar a indicação, ocasião em que

16 PONTES, Beatriz Oquendo. Do modelo de substituição de vontade ao modelo de apoio ao exercício da autonomia: a emergência da tomada de decisão apoiada. Dissertação de Mestrado. Programa de Pós-Graduação em Direito (Mestrado e Doutorado) da Universidade de Fortaleza. 2017, p.92. 
poderá até manifestar o interesse em extinguir a decisão apoiada (art.1.783-A, § $8^{\circ}$ ).

\section{DOS APOIADORES}

A lei estabelece que a pessoa que requer o apoio eleja pelo menos 2 (duas) pessoas idôneas que gozem de sua confiança e com as quais mantenha vínculos a fim de que sejam suas apoiadoras. Três, portanto, são os pressupostos expressamente apontados: a idoneidade, a confiança e o vínculo com o pretenso apoiado. A confiança necessariamente resultará exatamente desse vínculo relacional que o requerente tem com a pessoa indicada. Tal vínculo, por sua vez, não precisa ser jurídico, a exemplo do parentesco, da conjugalidade ou da convivência estável. Pode ser um vínculo de afetividade ou mesmo decorrente de uma experiência relacional concretizada no ambiente de trabalho.

Independentemente da previsão legal, o papel a ser desincumbido pelo apoiador requer a plena capacidade civil, sendo indispensável ainda que não haja entre ele e o apoiado eventual conflito de interesse. O juiz poderá, nesses casos, intimar o apoiado a substituir o apoiador, pois a escolha do apoiador é um ato personalíssimo, razão pela qual não é possível a nomeação ex officio.

Diversamente do que previu o Código Civil argentino ${ }^{17}$, que permite o apoio por apenas uma pessoa, o modelo brasileiro de TDA exige que se indiquem no mínimo dois apoiadores. Faz pressupor uma eventual pretensão do legislador em instituir um apoio compartilhado. Mas, como não há proibição expressa, acreditase possível que tais apoiadores ofereçam o suporte de modo conjunto fracionado ou conjunto compartilhado, ${ }^{18}$ à semelhança do que se permite na curatela, tudo nos termos estabelecidos no plano de apoio. O suporte conjunto compartilhado implicaria o exercício e a responsabilidade por todo o apoio igualmente atribuído a ambos os apoiadores, sem distinção de funções ou periodicidade. Já o suporte conjunto fracionado permitiria a que cada um fosse chamado a prestar seu

17 ARTíCULO 43.- Concepto. Función. Designación. Se entiende por apoyo cualquier medida de carácter judicial o extrajudicial que facilite a la persona que lo necesite la toma de decisiones para dirigir su persona, administrar sus bienes y celebrar actos jurídicos en general. Las medidas de apoyo tienen como función la de promover la autonomía y facilitar la comunicación, la comprensión y la manifestación de voluntad de la persona para el ejercicio de sus derechos. El interesado puede proponer al juez la designación de una o más personas de su confianza para que le presten apoyo. El juez debe evaluar los alcances de la designación y procurar la protección de la persona respecto de eventuales conflictos de intereses o influencia indebida. La resolución debe establecer la condición y la calidad de las medidas de apoyo y, de ser necesario, ser inscripta en el Registro de Estado Civil y Capacidad de las Personas. (grifo intencional).

18 ROSENVALD, Nelson. Curatela. Tratado de direito das famílias. Minas Gerais: IBDFAM, 2015, p. 773. 
Novos Estudos Jurídicos

apoio em áreas específicas, conforme suas próprias aptidões e habilidades, em relação às quais manteriam responsabilidade exclusiva. Justificada a solução mais adequada ao interesse do requerente, não se vê óbice à sua homologação.

Uma vez que o apoiador seja denunciado por agir com negligência, exercer pressão indevida em relação ao apoiado ou mesmo pelo inadimplemento de sua função, ouvida a pessoa apoiada e o Ministério Público, o juiz poderá destituí-lo, conforme art. 1.783-A, $\S 7^{\circ}$, determinando que o interessado indique novo apoiador.

$\mathrm{Na}$ hipótese em que a atuação negativa do apoiador resultar em prejuízo para o apoiado, terá ele o dever de reparar o dano, nos termos do art. 927 combinado com o art.186, do Código Civil. Trata-se, no caso, de responsabilidade civil subjetiva, vez que não se pode dispensar a prova da culpa na causação do dano. A responsabilidade civil objetiva resulta apenas do risco ou da previsão legal. Na omissão específica ao que foi consignado como dever do apoiador no termo de apoio homologado, seria possível se aplicar uma culpa presumida. Pois no caso, ter-se-ia uma espécie de obrigação de resultado.

Vale ressaltar, mais uma vez, a observação feita por Rosenvald, ${ }^{19}$ sobre a possibilidade de invalidação dos atos praticados em conflito de interesses ou sob pressão do apoiador, seja pela iniciativa do Ministério Público, da própria pessoa apoiada ou de seus herdeiros.

Também é facultado ao apoiador o direito de pedir o seu desligamento do processo de tomada decisão apoiada $(\$ 10) .{ }^{20}$ Sua exclusão está condicionada à manifestação do juiz e, nesse caso, à semelhança do que se exige do curador e do tutor, o apoiador deverá apresentar sua prestação de contas. ${ }^{21}$ À semelhança do curador, são obrigados a prestar contas de sua administração ao juiz, apresentando o balanço do respectivo ano (EPD, art. 84, §4%). Em todo caso, eventuais gastos com a elaboração dessas contas correrão por conta do apoiado (art. 1.761).

\section{DO OBJETO DO APOIO}

O apoio pode se estabelecer relativamente às questões patrimoniais e/

19 ROSENVALD, Nelson. Curatela. Tratado de direito das famílias. Minas Gerais: IBDFAM, 2015, p.759.

20 Art.1.783-A, §10. O apoiador pode solicitar ao juiz a exclusão de sua participação do processo de tomada de decisão apoiada, sendo seu desligamento condicionado à manifestação do juiz sobre a matéria.

21 Art.1.783, §11. Aplicam-se à tomada de decisão apoiada, no que couber, as disposições referentes à prestação de contas na curatela. 
ou às questões existenciais. Nada impede que incida, inclusive, nas decisões da rotina doméstica ou pertinentes aos cuidados pessoais em matéria de saúde. $A$ TDA seria um instrumento excelente para auxiliar a pessoa com deficiência na administração da casa, facilitando a operacionalização dos deveres materiais do casamento ou da paternidade, por exemplo. Mas é de se observar o que dispõe a lei: o apoio se concretiza na celebração de negócios jurídicos.

Entende-se que, ante a finalidade do instituto e a lacuna da lei, é possível ampliar o tipo de apoio para atender à necessidade específica de quem o requer. Pode consistir na facilitação da comunicação, na prestação de informação e nos esclarecimentos, no auxílio à análise dos fatores favoráveis e desfavoráveis que circundam certa decisão, etc., tudo a depender do caso específico e das demandas da pessoa que precisa do apoio.

Como o apoiador não ocupará a função de representante ou assistente, não haverá razão para aplicar a limitação do art. 85, $\$ 1^{\circ},{ }^{22}$ do EPD, pertinente à curatela.

No caso, não está em jogo a renúncia ao exercício de direitos fundamentais, tampouco a transmissão do exercício de direitos personalíssimos. Dessa forma é que se entende possível ao apoiador auxiliar o apoiado até no que diz respeito às decisões existenciais, tais como àquelas pertinentes ao casamento, ao divórcio, ao planejamento familiar, à educação, à saúde, etc.

Nos termos do art. 1.783-A, se o apoiador entender que o negócio jurídico trará riscos ou prejuízo relevante ao apoiado e quanto a isto houver divergência entre eles, poderá opor sua objeção ao Juiz que homologou o termo de apoio. Conhecendo a oposição que, entendo ser possível na forma de incidente processual, o Juiz determinará a oitiva do MP para ao final decidir. Nesse caso, a decisão pode impedir a celebração do negócio jurídico citado, operando uma certa modulação na capacidade civil do apoiador, daí a necessidade de oitiva do MP.

\section{EFEITOS PERANTE TERCEIROS}

Entende-se que a tomada de decisão apoiada é um acordo entre o apoiado e os apoiadores. Reafirma-se que a homologação da TDA não afeta a capacidade

22 EPD, Art. 85. A curatela afetará tão somente os atos relacionados aos direitos de natureza patrimonial e negocial. $\S 1^{\circ} \mathrm{A}$ definição da curatela não alcança o direito ao próprio corpo, à sexualidade, ao matrimônio, à privacidade, à educação, à saúde, ao trabalho e ao voto. 
Novos Estudos Jurídicos

de quem o requer, o apoiado conserva e conservará a sua capacidade civil incólume. Desta forma, os terceiros, por não participarem da relação jurídica entre apoiado e apoiador, por ela não podem ser alcançados nem prejudicados. Salvo nos limites do que impõe a própria medida. Ou seja, terceiros com quem o apoiado passa a ter algum tipo de negociação têm de suportar a presença do apoiador e aceitar a sua intervenção (art.1.783-A, § 1º). Assim, os negócios realizados com terceiros, pelo apoiado, mesmo sem a participação do apoiador, são válidos.

Porém, tendo conhecimento de que a pessoa está sob decisão apoiada, o contratante poderá solicitar que o(s) apoiador(es) venha(m) a assinar o contrato, fazendo constar no termo contratual a sua função em relação ao apoiado (art.1.783-A, § $5^{\circ}$ ). Mas essa exigência não condiciona a validade do ato/negócio firmado. É uma faculdade do contratante, caso saiba da existência da medida, pois a lei não determina que a sua homologação judicial seja seguida pelo respectivo registro no órgão de registro de pessoas naturais.

De acordo com o Projeto de Lei n.757/2015, que intenta alterar as modificações havidas no Código Civil pelo EPD, reafirma-se a validade dos negócios e atos jurídicos praticados pela pessoa apoiada, até mesmo quando celebrados sem a presença do apoiador e quando a providência prevista no parágrafo quinto não houver sido adotada. ${ }^{23}$

\section{DO ENCERRAMENTO}

O termo de tomada de decisão apoiada já deve informar o prazo de sua vigência (art.1.783-A, §1). Se não houver a prorrogação, a TDA se encerrará naquela data. Não obstante, a pessoa apoiada poderá, a qualquer tempo, requerer a extinção da medida, uma vez que preserva sua capacidade e autonomia. $O$ apoiador também poderá requerer ao juiz o término do acordo firmado, como autoriza o art. 1.783-A, §9. Nesse caso, o juiz ouvirá a pessoa beneficiária sobre sua intenção de continuar com a medida, determinando, se houver interesse, 23 Projeto de Lei do Senado no.757/2015 - Art. 2., Dê-se aos arts. 3o., 4o., 1.548, 1.767, 1.777 e 1.783-A da Lei no.10.406, de 10 de janeiro de 2002, a seguinte redação: (...) §12. Os negócios e os atos jurídicos praticados pela pessoa apoiada sem participação dos apoiadores são válidos, ainda que não tenha sido adotada a providência de que trata $\circ \S 5^{\circ}$ deste artigo. 
que possa indicar um novo nome para o encargo. A superveniência de curatela implicará o fim da tomada de decisão apoiada, especialmente se os limites daquela compreenderem o objeto do apoio.

\section{DA COEXISTÊNCIA COM A CURATELA}

Embora entenda que seria possível a coexistência de TDA com a curatela se o objeto do apoio não tivesse relação com os limites da curatela, não parece que essa solução prospere. O PLS 757 dispõe textualmente que a TDA sucumbe ou não pode ser homologada quando o apoiado estiver sob curatela. Pelo art. $2^{\circ}$, que propõe alteração em alguns dispositivos do CC, o art.1.783-A teria novos parágrafos, dentre os quais o que declara a incompatibilidade entre TDA e Curatela. ${ }^{24}$

\section{SERIA VIÁVEL A TDA POR ESCRITURA PÚBLICA?}

No Brasil, inclusive, para reduzir as demandas judiciais, alguns procedimentos passaram a ser admitidos na via extrajudicial. A título de exemplo, o Código Civil de 2002 permitiu a emancipação do menor por escritura pública, quando anteriormente só era possível na via judicial (CC, art. $5^{\circ}$, parágrafo único, inciso I). De igual forma, permite o uso da escritura pública para o reconhecimento do filho (CC, art.1.609, II); o divórcio, a separação judicial e a extinção de união estável (CPC, art.733, caput e §10.); o inventário e a partilha (CPC, art. 610, §10.) e o usucapião administrativo (CPC, art.1.071 que introduz o art. 216-A na Lei n. $6.015 / 73)$. Sem mencionar a retificação registral imobiliária pela via administrativa que se tornou possível com o advento da Lei n. 10.931/2004.

A despeito disso, o acordo de decisão apoiada foi admitido entre nós por meio de um processo judicial, seguindo o procedimento de jurisdição voluntária. Uma vez que se fará por meio desse procedimento, a "lei impede que os titulares dos interesses ali referidos possam livremente negociá-los", exigindo a atividade integrativa do juiz, sem a qual o negócio jurídico de direito privado 
não se constituirá. ${ }^{25}$ Sob esse modelo, a TDA parece incompatível com a ratio da Convenção que procura exalta e promover a autonomia da pessoa.

Rosenvald ${ }^{26}$ chega a mencionar que o termo de apoio possa ser lavrado por meio de escritura pública na sua fase inaugural, exigindo, de todo modo, a sua homologação judicial para que possa se consolidar. Ou seja, dispõe que o acordo de apoio seja lavrado por escritura pública e apensado à petição que requer a sua homologação judicial. Mas esse modo de operar em nada amplia a autonomia da pessoa que ainda necessitará da atuação integrativa do juiz para ver os efeitos daquele negócio jurídico. Importará apenas mais um custo de tempo e de dinheiro, já que o apoio pode ter todos os seus termos informados na própria peça inicial.

Estranha-se que o ordenamento pátrio conceda à pessoa com deficiência plena capacidade, em igualdade com as demais, para contratar nas diversas modalidades possíveis, inclusive para comprar e vender bens imóveis, casar e viver união estável, divorciar-se ou separar-se por meio de escritura pública, elaborar testamento, mas não Ihe faculte a possibilidade de acordar um apoio específico com pessoas que reputa ser de sua confiança. ${ }^{27} \mathrm{O}$ Estado não investiga sobre a pessoa do eventual nubente, mas entrevista um possível apoiador, cujo apoio será específico e temporário.

Ademais, em quaisquer dos atos que sejam celebrados na presença do notário ou tabelião, este deverá ter a cautela de examinar pessoal e documentalmente se as partes envolvidas possuem a necessária capacidade civil (CC, art. 215, §1, II e IV) e, dito de modo mais claro, se ostentam, grosso modo e conforme a experiência ordinária, o discernimento necessário. Embora não possa fazer um juízo subjetivo e abstrato sobre a capacidade de discernir da pessoa que procura os serviços notariais ou cartorários, apenas em virtude da deficiência, sob risco de incorrer em discriminação como dispõe o art. 83, da Lei no.13.146/2015, poderá recusar a lavratura da escritura se o declarante não conseguir manifestar a sua vontade de modo escorreito, socorrendo-se do que instrui a Resolução

$\overline{25}$ LOURENÇO, Haroldo. Manual de direito processual civil. Forense: São Paulo, 2013, p.61.

26 ROSENVALD, Nelson. Novas reflexões sobre a tomada de decisão apoiada: como conciliar autonomia, cuidado e confiança. Revista IBDFAM: Família e sucessões. Ibdfam: Belo Horizonte, 2017, p.70.

27 PONTES, Beatriz Oquendo. Do modelo de substituição de vontade ao modelo de apoio ao exercício da autonomia: a emergência da tomada de decisão apoiada. Dissertação de Mestrado. Programa de Pós-Graduação em Direito (Mestrado e Doutorado) da Universidade de Fortaleza. 2017, p.102. 
CNJ no.35/2007, art. 46. ${ }^{28}$ Em outros casos mais específicos, para a lavratura da escritura exige a certidão negativa de incapacidade. ${ }^{29}$

Nas críticas de Nevares e Schreiber, exigir-se que a TDA se faça por meio de processo judicial pode afastar o interesse pelo instituto, pois terá de enfrentar a máquina do judiciário com as inconveniências da demora e os custos que lhes são pertinentes.

Respeitadas as diferenças intrínsecas a cada experiência estrangeira, é indubitável que a judicialização da tomada de decisão apoiada em um país como o Brasil, em que a celeridade na tramitação dos processos judiciais ainda é um objetivo que se está distante de alcançar, traz significativo risco de desinteresse sobre o novo instituto(...). O Estatuto que em tantas passagens declara em alto e bom tom que o deficiente é capaz parece ter se esquecido disto, ao desenhar a tomada de decisão apoiada. Como capaz, há instrumentos contratuais à sua disposição os quais dispensam a submissão a um processo judicial, com todas as agruras que o ingresso em juízo implica, especialmente para a população mais carente de recursos econômicos e, mais necessitada, em larga medida, da proteção que o Estatuto deveria oferecer. ${ }^{30}$

Na experiência estrangeira, há exemplos em que o apoio pode se consolidar sem a participação do judiciário, seria o caso da Representation Agreement Act, no Canadá e da Sauvegard de Justice, na França.

No Peru, tramita um projeto de lei (n. 876/2016) que visa à alteração do Código Civil, do Código de Processo Civil e da Lei do Notariado, prevendo a possibilidade do acordo de apoio por meio de escritura pública. ${ }^{31} \mathrm{~A}$ proposta de alteração legislativa traria a seguinte redação para o art.568 do Código Civil Peruano,

28 Resolução CNJ no.35/2007, Art. 46. O tabelião poderá se negar a lavrar a escritura de separação ou divórcio se houver fundados indícios de prejuízo a um dos cônjuges ou em caso de dúvidas sobre a declaração de vontade, fundamentando a recusa por escrito.

29 O Código Notarial do Estado do Ceará, instituído pelo Provimento no.8/2014 da Corregedoria Geral de Justiça do Estado do Ceará, dispõe no art.383, inciso XXI: "Art. 383 - Nas escrituras relativas a imóveis, devem ser observadas as disposições do Decreto-Lei n 93.240/86, consignando-se, ainda: XXI - deverá ser apresentada certidão negativa de incapacidade civil do alienante, no caso de escrituras públicas que envolva compra e venda de imóvel, pelo período de 10 (dez) anos e validade de 30 (trinta) dias, contados de sua expedição."

30 SCHREIBER, Anderson e NEVARES, Ana Luiza Maia. Do sujeito à pessoa: uma análise da incapacidade civil. In O direito civil entre o sujeito e a pessoa: estudos em homenagem ao Professor Stéfano Rodotà. TEPEDINO, Gustavo; TEIXEIRA, Ana Carolina Brochado; ALMEIDA, Vitor (Coord.). Forúm: Belo Horizonte, 2016, p. 52-53.

31 Disponível em: <http://www2.congreso.gob.pe/Sicr/RelatAgenda/proapro.nsf/Proyectos AprobadosPortal/4F7CA4 649D23EF6C052577F90068945C/\$FILE/2361Tuteladelincapazoadultomayor.pdf > Acesso em: 12 dez. 2017. 
Artículo 568 - "La persona mayor de edad que requiera asistencia para el ejercicio de su capacidad jurídica puede designar ante una notaría o gratuitamente ante un juez de paz letrado una o más personas de apoyo de su confianza. Deben prestarse las medidas de accesibilidad y los ajustes razonables necesarios para la realización de este acto. El registro notarial o judicial de los apoyos debe ser accesible y en ningún caso significará un condicionamiento para el ejercicio de la capacidad jurídica".

Por meio de escritura pública, o negócio jurídico se concluiria apenas com as figuras do apoiado e do apoiador, na medida em que declarassem sua vontade na presença do notário. Sem o Judiciário, sem o Ministério Público.

Em face das críticas apontadas pela ONU ao sistema adotado pelo Brasil e, considerando toda a tendência de apostar nas soluções extrajudiciais, por que o legislador brasileiro preferiu uma tomada de decisão apoiada controlada pelo judiciário? Haveria alguma justificativa plausível? E por que ainda previu a intervenção do Ministério Público?

Há certo paternalismo jurídico que pressupõe a vulnerabilidade da pessoa que pretende o apoio. Nesse sentido, ao homologar o acordo, o Judiciário conhece a pessoa que o pretende, os apoiadores escolhidos, exerce certo controle sobre eventual conflito de interesses que estes possam ostentar em relação àquele, assiste ao compromisso dos apoiadores e estabelece a prevenção para ulterior e eventual oposição formulada pelo apoiador à celebração de negócio jurídico pelo apoiado, nos casos do art. 1.783-A, § 6. Com esse conhecimento prévio, imagina-se facilitar a propositura dessa eventual oposição que, por sua vez, somente poderá produzir efeitos na seara do Judiciário e com a participação do Ministério Público. Explica-se o porquê.

Se o apoiador discordar do apoiado por entender que o negócio jurídico que este pretende celebrar oferece-lhe riscos ou prejuízo relevante, deverá comunicar ao juiz que, após ouvir o Ministério Público, decidirá sobre a questão. Esta possibilidade é um efeito prático e relevante da TODA, que faz do apoiador alguém capaz de provocar uma intervenção na autonomia e na capacidade civil do apoiado. A julgar pertinente as razões do apoiador, o juiz tocará a autonomia do apoiado, impedindo-Ihe de concluir aquele negócio jurídico específico. Restringirá a capacidade civil do apoiado, ainda que muito pontualmente! Justificável, nesse 
momento, a participação do Ministério Público com fundamento jurídico, que estaria no art.178, II, do Código de Processo Civil. ${ }^{32}$

\section{CONSIDERAÇÕES FINAIS}

Como a TDA é um instituto novo, ainda está na fase de acomodação tanto por parte dos aplicadores do direito como também pelos sujeitos que dela podem fazer uso. É importante, porém, que na sua aplicação, seja respeitado o seu perfil funcional, que é o de conferir apoio ao melhor exercício da capacidade civil do apoiado, respeitando-lhe a autonomia nos termos que apregoa a Convenção sobre os Direitos da Pessoa com Deficiência.

A premissa geral da qual se deve partir está na ratio da CDPD, voltada para a promoção da autonomia da pessoa com deficiência, da qual advém a segunda premissa, que é a mudança que se produziu no sistema protetivo que migra do sistema de representação, firmado na substituição de vontade, para o modelo do apoio, firmado na primazia da vontade do sujeito.

Conhecidas essas premissas, a TDA pode ser compreendida como a alternativa que de modo mais concreto realiza a principiologia da CDPD reconhecer a autonomia e a capacidade da pessoa com deficiência sem deixá-la sozinha. $\mathrm{O}$ apoiador será alguém presente o suficiente para facilitar o exercício da autonomia pela pessoa apoiada e apto processualmente para intervir na sua proteção, obstando a celebração de negócios que Ihes sejam prejudiciais.

O apoiador não é um curador, tampouco um mandatário ou um gestor de negócios.

Em virtude da expansão que a CDPD procurou conceder à autonomia da pessoa, questiona-se a exigência de que a TDA seja homologada judicialmente. Poderia ser realizada por simples escritura pública, uma vez que a pessoa que requer o apoio é dotada de capacidade civil.

32 CPC, "Art. 178 O Ministério Público será intimado para, no prazo de 30 (trinta) dias, intervir como fiscal da ordem jurídica nas hipóteses previstas em lei ou na Constituição Federal e nos processos que envolvam: (...) II - interesse de incapaz.". 
BANDEIRA, Paula Greco. Notas sobre a autocuratela e Estatuto da Pessoa com Deficiência. In: MENEZES, Joyceane B. Direito da pessoa com deficiência intelectual e psíquica nas relações privadas. Convenção sobre os direitos da pessoa com deficiência e Lei Brasileira de Inclusão. Rio de Janeiro: Processo, 2016, p. 569-592.

GAGLIANO, Pablo Stolze. É o fim da interdição? Artigo retirado do site http:// professorflaviotartuce.blogspot.com.br/2016/02/e-o-fim-da-interdicao-artigo-de-pablo. html. Acesso em: 20 dez. 2017.

HERNANDEZ, Angel Sanchez. El artículo 223.2. ${ }^{\circ}$ del Código Civil: La autotutela y su necesidad en nuestra sociedad. Revista Crítica de Derecho Inmobiliario, N. ${ }^{\circ}$ 736, págs. 861 a 886. Disponível em: < https://libros-revistas-derecho.vlex.es/vid/arta-culo-civil-autotutelanecesidad-439674310>. Acesso em: 12 dez. 2017.

MENEZES, Joyceane Bezerra de. O direito protetivo no Brasil após a convenção sobre a proteção da pessoa com deficiência: impactos do novo CPC e do estatuto da pessoa com deficiência. Civilistica.com. Rio de Janeiro, a. 4, n. 1, jan./jun. 2015. Disponível em: <http:// civilistica.com/o-direito-protetivo-no-brasil/>. Acesso em: 01 dez. 2017.

MENEZES, Joyceane Bezerra de. O novo instituto da Tomada de Decisão Apoiada: instrumento de apoio ao exercício da capacidade civil da pessoa com deficiência instituído pelo Estatuto da Pessoa com Deficiência - Lei Brasileira de Inclusão (Lei no.13.146/2015). MENEZES, Joyceane B. Direito da pessoa com deficiência intelectual e psíquica nas relações privadas. Convenção sobre os direitos da pessoa com deficiência e Lei Brasileira de Inclusão. Rio de Janeiro: Processo, 2016.

NACIONES UNIDAS. Comité sobre los Derechos de las Personas con Discapacidad. Observaciones finales sobre el informe inicial del Brasil. Disponível em: < https://documentsdds-ny.un.org/doc/UNDOC/GEN/G15/220/78/PDF/G1522078.pdf?OpenElement>. Acesso em: 16 set. 2017.

LOURENÇO, Haroldo. Manual de direito processual civil. São Paulo: Forense, 2013.

PONTES, Beatriz Oquendo. Do modelo de substituição de vontade ao modelo de apoio ao exercício da autonomia: a emergência da tomada de decisão apoiada. Dissertação de Mestrado. Programa de Pós-Graduação em Direito (Mestrado e Doutorado) da Universidade de Fortaleza. 2017.

ROSENVALD, Nelson. Curatela. Tratado de direito das famílias. Minas Gerais: IBDFAM, 2015.

ROSENVALD, Nelson. Novas reflexões sobre a tomada de decisão apoiada: como conciliar autonomia, cuidado e confiança. Revista IBDFAM: Família e sucessões. Belo Horizonte: IBDFAM, 2017.

ROIG, Rafael Asís. Sobre capacidade y derechos. In: AVILÉS, María del Carmen Barranco; ANGÓN, Oscar Celador y FERNANDEZ, Félix Vaca (Coord.). Perspectivas atuales sobre los sujetos de derechos. Madrid: Dikinson, 2012, p.37-56. 
SCHREIBER, Anderson; NEVARES, Ana Luiza Maia. Do sujeito à pessoa: uma análise da incapacidade civil. In: TEPEDINO, Gustavo; TEIXEIRA, Ana Carolina Brochado; ALMEIDA, Vitor (Coord.). O direito civil entre o sujeito e a pessoa: estudos em homenagem ao Professor Stéfano Rodotà. Belo Horizonte: Fórum, 2016.

TEIXEIRA, Ana Carolina Brochado; RETTORE, Anna Cristina de Carvalho e SILVA, Beatriz de Almeida Borges e. Reflexões sobre a autocuratela na perspectiva dos planos do negócio jurídico. In: MENEZES, Joyceane B. Direito da pessoa com deficiência intelectual e psíquica nas relações privadas. Convenção sobre os direitos da pessoa com deficiência e Lei Brasileira de Inclusão. Rio de Janeiro: Processo, 2016.

Recebido em: abril/2018

Aprovado em: agosto/2018 